Meta

Journal des traducteurs

Translators' Journal

\title{
Action et demande en justice : une confusion courante
}

\section{Louise Langevin et André Thauvette}

Volume 14, numéro 1, mars 1969

URI : https://id.erudit.org/iderudit/004473ar

DOI : https://doi.org/10.7202/004473ar

Aller au sommaire du numéro

Éditeur(s)

Les Presses de l'Université de Montréal

ISSN

0026-0452 (imprimé)

1492-1421 (numérique)

Découvrir la revue

Citer cet article

Langevin, L. \& Thauvette, A. (1969). Action et demande en justice : une confusion courante. Meta, 14(1), 43-44. https://doi.org/10.7202/004473ar d'utilisation que vous pouvez consulter en ligne.

https://apropos.erudit.org/fr/usagers/politique-dutilisation/ 
ACTION ET DEMANDE EN JUSTICE:

UNE CONFUSION COURANTE

Selon Solus et Perrot: «La demande en justice est l'acte de procédure par lequel le titulaire d'une action exerce effectivement le pouvoir qui lui est donné par la loi de saisir un juge... Ainsi définie, la demande en justice correspond techniquement à une notion bien précise qu'il ne faut pas confondre avec l'action qui lui a donné naissance. Tandis que l'action est une voie de droit, c'est-à-dire un pouvoir légal, la demande en justice est l'acte par lequel une personne use de ce pouvoir. ${ }^{1}$

D'après les définitions de ces deux grands auteurs de droit judiciaire privé, il faut donc rejeter les expressions habituelles si chères aux avocats, aux juges, aux traducteurs juridiques et même aux profanes, telles que: « votre action est rejetée », «intenter une action», "un droit d'action», "se désister de son action » et encore bien d'autres. Étudions ces expressions une à une et voyons pourquoi elles sont à bannir de notre discours.

On devrait dire la demande est rejetée et non «l'action est rejetée », car un pouvoir (l'action) est ou n'est pas, il ne s'agit pas de le rejeter ou de l'accepter. Par exemple si un mineur s'adresse seul à un tribunal, bien qu'il n'en ait le droit qu'accompagné de son tuteur, on doit rejeter sa demande et non son action.

Si intenter signifie: entreprendre contre quelqu'un ${ }^{2}$, on ne peut «intenter une action» (sauf dans le cas d'actions nommées comme l'action pétitoire, possessoire, paulienne, etc.), car on entreprend un acte et non un pouvoir contre quelqu'un. Le Petit Robert lui-même s'y laisse prendre; il devrait remplacer «action» par demande dans la locution suivante: "intenter une ac'ion ... » ${ }^{3}$.

L'action étant un pouvoir, une voie de droit ${ }^{4}$, l'expression un «droit d'action 》 est tautologique. Cet exemple nous montre à quel point la confusion est grande.

Un avocat se désistant de son action renoncerait à son pouvoir de s'adresser au tribunal pour la cause en cours. Or l'avocat ne veut souvent se désister que de sa demande et conserver peut-être son pouvoir de s'adresser au tribunal dans une demande mieux formulée.

Mais peut-on blâmer les juges, les avocats et les traducteurs juridiques lorsque le texte dont ils s'inspirent, le Code de procédure civile, est lui-même fautif. Nous avons parcouru le Code et nous y avons relevé entre autres les exemples suivants:

Article 110: ... une action commence par un bref d'assignation au nom du

Souverain.

Article 176: ... la défense produite à une action.

Article 75: Si l'action est formée contre plusieurs défendeurs.

Dans tous les cas, il aurait fallu employer demande au lieu d'action.

D'où vient cette confusion? En lisant la version anglaise du Code de procédure civile, nous observons que l'anglais ne fait aucune différence entre les termes action et demand; nous rencontrons: "The object of the demand ... $\gg^{5}$

1. Henry Solus et Roger Perrot, Droit judiciaire privé, Paris, Sirey, 1961, p. 109.

2. Paul Robert, Petit Robert, Paris, Société du Nouveau Littré, 1967, p. 922.

3. Ibid., p. 922.

4. Henry Solus et Roger Perrot, op. cit.

5. Code de procédure civile, 1965 , art. 117. 
aussi bien que $"$ No action will be dismissed ... ${ }^{6}$. Les deux termes doivent se traduire par demande puisqu'il s'agit ici de l'exercice du pouvoir. Ainsi cette inexactitude dans l'emploi des termes français vient peut-être d'une mauvaise traduction. Que cette seule hypothèse mette en garde les traducteurs. Lorsqu'ils traduisent les termes action et demand, ils doivent avoir en tête la distinction établie par Solus et Perrot, et se demander s'il est question du pouvoir de s'adresser en justice ou de l'exercice de ce pouvoir.

Louise Langevin et André Thauvette

6. Code de procédure civile, 1965 , art. 462. 